\title{
Effect of multimedia in teaching Science at secondary level
}

Bishnu Kumar Dahal

\section{Abstract}

The aim of this study was to investigate the effect of multimedia in teaching Science at Secondary School and attitudes toward Information and Communication Technology (ICT). The study was an experimental research design with two groups employing a pre-test and post-test. The sample schools were two public secondary school of Lalitpur district. Participants were 68 students from grade 10 studying Science from two schools. Furthermore, five science teachers in that school were also taken as samples for an interview session. The data were analyzed through statistical devices, such as mean, standard deviation, variance, t-test and chi-square test. The differences between means were computed by using two tailed t-test at 0.05 level of significance. The results indicated that the mean achievement of the group using multimedia projector was significantly better than the group without using multimedia projector. The findings of this study therefore provided strong evidence to support the use of ICT, particularly multimedia technology, in the teaching and learning of Science among secondary school students. Furthermore, the results also showed that the secondary level science teachers have positive attitude towards ICT in teaching science in the classroom.

Keywords: ICT, learning, multimedia, Science, secondary level, teaching

\section{Introduction}

The term 'multimedia,' which is constituted by 'multi' - means integrating many expression methods and 'media' - which implies technical words such as computer, dialogue, and digital, has changed its meaning through the decades. The term multimedia can be defined as a platform that integrates analogue information in various forms such as text, images, and audio-visual materials to a single digitized data and relays them using several (multi) vehicles (media). It is a system that allows users the use of easy and high-speed information communication networks. Multimedia is the exciting combination of computer hardware and software that allows to integrate video, animation, audio, graphics, and test resources to develop effective presentations on an affordable desktop computer(Fenrich, 1998).

The presence of multimedia technology opens a new era in the development of teaching and learning science. The ability of multimedia technology in combining various kinds of media like text, audio, picture, numeric, animation, and video in the form of digital software, and its interactive capacity make it an interesting alternative of learning aids. Multimedia is considered as an impressive learning medium because of its capability in activating our perception such as our sight, our hearing, and our tactile. With the arts, children learn to see. We want our children to have basic skills. But they will also need sophisticated cognition, and they can learn that through the visual arts(National Art Education Association, 2011).For this reason, researchers tried to apply other methods of teaching that can increase the effectiveness of teaching science education. The findings by Junaidu (2008)for five year's offerings show that students consistently perform much better in questions requiring application of material taught in carefully animated algorithms. These results should carry over to other educational environments.

It has been found in both pre-school and primary schools of Australia that the use of drill practices software has shown to increase learner's achievements. In the secondary schools, 
it was found that the use of Information and Communication Technology (ICT) tool supports higher order thinking skills contribute positively towards science achievements (Somekh et al., 2007). Long before the Internet was launched, distance courses were being offered to provide education on particular subject or skills.

One of the significant applications of computer is Computer Assisted Instruction (CAI). It is nothing but giving instruction with the help of computers. In CAI the activity of the learner is the most important attribute (Rajasekar \& Vaiyapuri, 2008). It has been developed from the principles of programmed instruction and can be done in many different modes like, tutorial mode, drill and practice mode, simulation mode, discovery mode, gaming mode etc.(Vanaja \& Rajasekar, 2007).

In the context of Nepal, computer technology training has been started since1971 $\mathrm{AD}$ from National Computer Centre. It is the day of computer technology in education. But computer technology has been used in school level since1992 AD. More than 20 years further on while we celebrate the computer do offer new capacities to learn both inside and outside the classroom. The use of ICT tools in teaching learning of Science has long been studied. Most of the Nepali homes did not use computer and over two thirds are not connected to the web. Most of the studies are confined to developed countries only(Sapkota, 2015).

Previously, teachers had to rely exclusively on books for plans and information. Now they can search the World Wide Web for many of their educational needs. They can provide opportunities for students to complete group projects based solely on primary sources, allowing students to construct their own knowledge(Taber, 2006). The technology can be used to bridge the gap between traditionalist and constructivist by allowing both to flourish simultaneously(Mohan, 2013).

Most of the secondary school students are looking for more of the multimedia in Science education(Musker, 2004). Multimedia technique is considered as important in Science education and other subjects. Many parents do not have an idea to encourage their children in choosing multimedia technique education in their subjects. Students are not interested to study Science education because for them, Science education is very difficult and nothing more than drawing and coloring, tedious, requires a high skill, requires a lot of money and takes a long time to complete the work. Among parents also, they see the multimedia approach education as not contributing to future their children. The teaching methods used and the teacher, who is non-options to teach multimedia technique education, has limited ability to develop the talents of students in producing quality scientific work. The traditional method used has reduced students' interest to learn multimedia approach in Science education.

In the context of Nepal, a number of research studies have been conducted in the field of effectiveness of multimedia in teaching and learning process. The studies were found to be limited to other fields of subject. However, these research studies were not directed towards the use of multimedia in Science through pedagogical process. Hence, in this study researcher has focused on the effect of multimedia in teaching Science among secondary school students.

The main purposes of this study were to examine the effects of multimedia in teaching Astronomy and Geology in Science and to identify attitude of Science teachers towards the ICT at secondary level. The research questions answered in this study were as follows: 
1. Is there any effect of multimedia in teaching Science, specially Astronomy and Geology in Science at secondary level?

2. Do teacher and students have the same attitudes towards multimedia in teaching science?

The findings of the study would provide information about the effect of multimedia in teaching Science at secondary level. They can also be used as a guide for teachers to manage their teaching and learning in class among secondary students. This is crucial for preparing future teachers to be ready to teach their students in this new era of technologies. The study would, therefore, try to provide some feedback from students concerning the use of multimedia in teaching and learning at school.

\section{Literature Review}

Interactive multimedia courseware was an effective and useful learning material and had complemented the print modules provided to the learners(Abas, Osman, Kumar, \& Thangapragasam, 2007). Multimedia courseware is one of the solutions in dealing with students' differences in learning styles and knowledge background since it integrates media elements that can engage human information retrieval methods which are visual, auditory, reading and kinesthetic(Syazwan, Wan Ahmad, \& Yew, 2011). The influence of information technology in the education setting and specifically the capability of multimedia technology increases the students' interest in learning. Multimedia technology is able to motivate children to learn due to the fact that such a technology can touch various modalities of the children. The use of Motivate Literacy is more effective in motivating children towards literacy than conventional literacy materials(Munir, n.d.). Due to the rapid expansiveness of the technology and its wide array of uses, the incorporation of technology in learning has become a viable and inexpensive option. As a result, it is becoming increasingly clear that traditional textbooks will be cast aside and the adoption of the e-book will result(Gertner, 2011).

Multimedia technology has the potential and functionality to hold enjoyment for users compared to that of a standard textbook (Gertner, 2011). Multimedia-assisted teaching and learning have become standard forms of education(Leser, Baca, \& Uhlig, 2011).

In addition, Shah and Khan (2015)believed that multimedia-aided teaching is more effective than the traditional one. For this reason, they have recommended multimedia should be provided to schools for teaching science subjects and infrastructure should be provided to schools for the implementation of multimedia-aided teaching. They have also argued that students' attitude towards science improves more if multimedia-aided teaching methodis adopted as compared to the traditional method of teaching. Furthermore, Neupane (2014) argued that with the advent of inexpensive technology and multimedia resources, effective teaching materials for improvement of science education can be accessed with a much smallerbudget than was previously possible.

In teacher driven education, multimedia lessons were found to be effective in teaching road signs and speed limits and produced higher levels of performance than non-multimedia instruction(Lee \& Keckley, 2006). This highlights that the unique characteristics of a subject influence the success of learning via picture or audio presentations(Nugent, 1982).

Multimedia has succeeded in psychomotor development and strengthening of visual processing of the intended users in multi-disciplinary multimedia educational programmers where DVDs were also used as multimedia technology(Malik \& Agarwal, 2012). The inclusion 
of on-screen information sources proposes opposite reactions to traditional historical printed text and contributes to the development of critical and objective skills development(Lee, 2002).Visual multimedia explanations may help to distinguish between primary and secondary sources, especially when application of knowledge is required to answer questions (Eeden, 1999).

\section{Theoretical Foundation}

In this study, the researcher had used Ellis's Model for Multimedia Effectiveness, Cognitive Theory and Cognitive - Constructive Theory of multimedia learning as theoretical foundation. Ellis's Model for Multimedia Effectiveness

According to this model, any study of the effectiveness of multimedia as a tool to enhance learning must specify learning in a manner that is consistent with accepted learning theory, the student population under consideration, the subject matter being studied, and which media elements are being studied, at what level of interactivity, and toward what end. Cognitive Theory of Multimedia Learning

According to Mayer and Moreno (1998)and Mayer (2003), Cognitive Theory of Multimedia Learning (CTML) is based on three assumptions: the dual-channel assumption, the limited capacity assumption, and the active processing assumption. The dual-channel assumption is that working memory has auditory and visual channels based on Baddeley's(1983) theory of working memory and Paivio's(Clark \& Paivio, 1991; Paivio, 1986)dual coding theory. Second, the limited capacity assumption is based on cognitive load theory (Sweller, 1988, 1994)and states that each subsystem of working memory has a limited capacity. The third assumption is the active processing assumption which suggests that people construct knowledge in meaningful ways when they pay attention to the relevant material; organize it into a coherent mental structure, and integrate it with their prior knowledge (Mayer, 1996, 1999).

According to CTML, the visual information processing channel may become overloaded when students must process on-screen graphics and on-screen text at the same time. However, when words are presented as narration, words can be processed in the verbal channel, thereby reducing the cognitive load in the visual channel (Mayer, 2005).

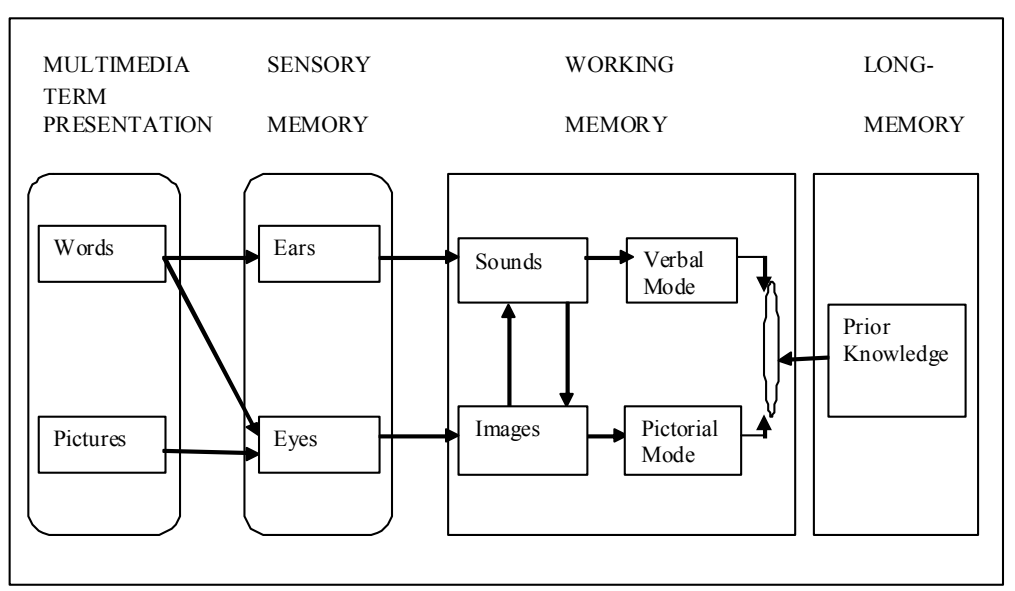

Figure 1.The Cognitive Theory of Multimedia Learning (Mayer, 2005) 
Figure 1 represents the cognitive model of multimedia learning of the human information processing system. The boxes represent memory stores, being sensory, shortterm and long-term memory(Mayer, 2002, 2005; Moreno, 2004).During the cognitive process of integrating, the learner mentally connects the verbal and pictorial models as well as the applicable prior knowledge from the long-term memory (Mayer, 2002).Based on Mayer's assumptions and research, the cognitive theory related to multimedia learning has shown how people construct knowledge from words and pictures (Mayer \& Moreno, 2003). Research has revealed that deeper learning is achieved when the following multimedia combinations are used: text and picture explanations rather than verbal explanations; exclusion of irrelevant words, sounds and video; avoidance of complex verbal and pictorial representations with no guidance for low-prior knowledge learners; and words presented in a personalized conversational style, rather than a detailed description style(Mayer, 2002).

\section{Cognitive-Constructivist Theory of Multimedia Learning}

The constructivist theory of instruction is based on principles of learning that were derived from branches of cognitive science. The constructivist teaching approach theory makes effective use of students' prior knowledge and cognitive structures based on those experiences(Bull, 2012; Mayer, Moreno, Boire, \& Vagge, 1999). An example of what this means for designing interactive digital learning materials in that images, animations, pictures and graphics used should relate to student's prior experiences.

\section{Conceptual Framework}

The following was the conceptual frameworks on effect of multimedia in teaching science. In this study, manipulating variable was multimedia approach in teaching science and dependent variables were achievement and attitude towards ICT. However, various intervening extraneous variables such as learners' characteristics, teachers' characteristics, and classroom environment may affect the expected outcomes which were controlled during study.

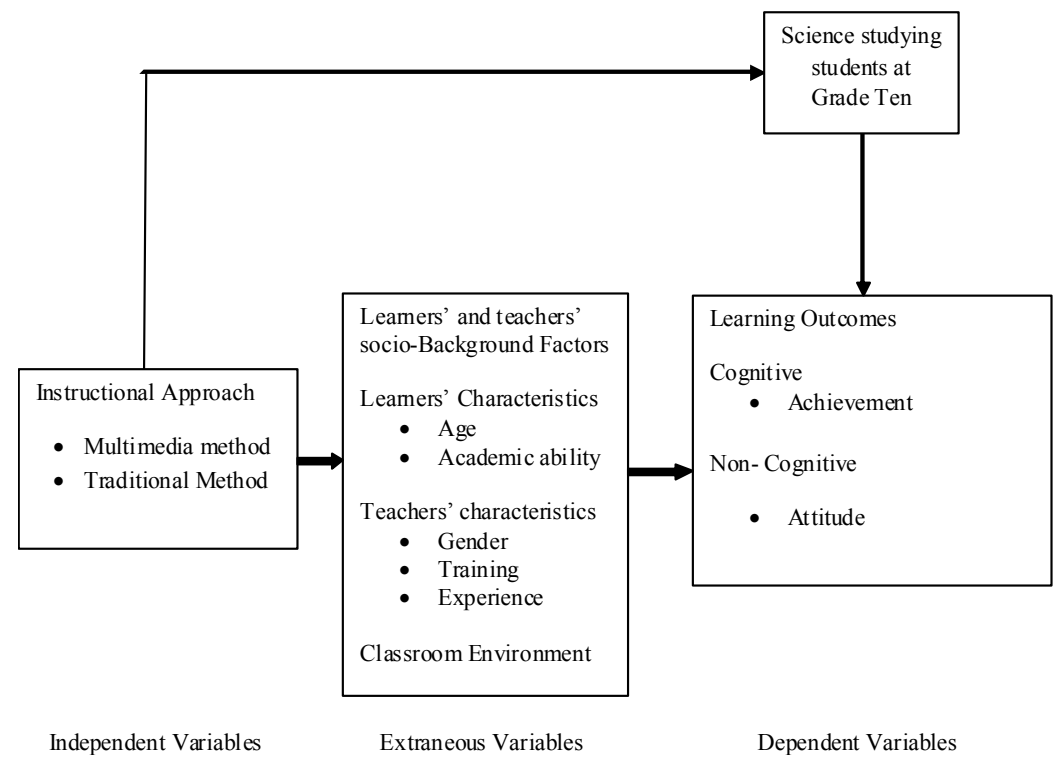

Figure 2.Conceptual Framework of the Study. 


\section{Methodology}

The research design used in this study is experimental research, which includes the pre-test and post-test.

The target population of this study was students of grade 10 studying science in public secondary school in Lalitpur district. The number of the total samples was 68 students. A control group containing 34 students received no treatment and an experimental group with same number of students received treatment. Furthermore, five science teachers selected randomly in that school were also taken as samples for an interview session.

One set of achievement test item constituting of 50 objective type questions related to the selected topics Astronomy and Geology were utilized as tool for primary data collection. The test items included multiple choice questions having four distracters with only one correct response. The content validity of the test questions was established and approved by the University professor, Lecturer as well as school science teacher. For the reliability of the test item, difficulty level of test item was found by pilot study which was carried out with 17 students of grade ten of non-sample school of study area.

The attitude scale was provided to the teachers' individually and they were requested to tick on one of SA, A, N, DA, SDA, where SA was for strong agreement, A for agreement, $\mathrm{N}$ for neutral, DA for disagreement and SDA for strong disagreement. For positive statement SA, A, N, DA, SDA implied 5, 4, 3, 2, 1 point respectively. In this scale there was neither 'right' nor 'wrong' answers as it measures degree of agreement or disagreement of sampled teachers' toward the question.

For data collection, first of all researcher visited the sample school and established a rapport with school family. The researcher explained the purpose of study and requested the authority for co-operation to conduct an achievement test on grade ten students (sample class) for one week. Two groups of students were selected from grade ten by random sampling method.

At the beginning pre-test was conducted to both control and experimental groups of each sample school. At the end of instructional periods, the achievement (post-test) was administrated to both groups of sample students with the help of school administration. Then the result of pre-test and post-test of both groups were tabulated and compared. During the pre-test and post-test, the extraneous variables were controlled as far as possible.

\section{Result and Discussion}

Results of pre-test scores obtained by all without using multimedia projector and all with using multimedia projector group students

The pre-test mean scores, standard deviation, variance and t-value of the scores obtained by Control Group and Experimental group students are given below.

Table 1. Results of pre-test scores obtained by all without using multimedia projector and all with using multimedia projector group students

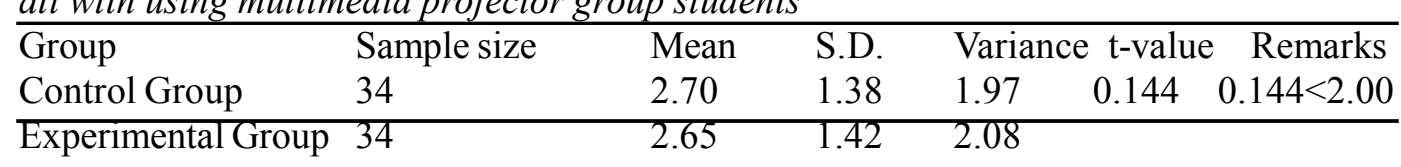

$\mathrm{t}_{0.05,66=2.00}$ 
Table 1 shows that the mean scores of pre-test of control group and experimental group students were 2.7 and 2.65 respectively. The calculated standard deviation and variance were found to be 1.38 and 1.97 for control group respectively. While the calculated standard deviation and variances were found to be 1.42 and 2.08 for experimental group respectively. The calculated $t$-value was found to be 0.144 which is less than the tabulated value $(t=2.00)$ at 0.05 level of significance using two tailed test with degree of freedom 66.This shows that there was no significant difference between control group and experimental group students' achievement before treatment.

Results of post-test scores obtained by all without using multimedia projector and all with using multimedia projector group students

The post-test mean scores, standard deviation, variance and t-value of the scores obtained by Control Group and Experimental group students are given below. Table 2. Results of post-test scores obtained by all without using multimedia projector and all with using multimedia projector group students

\begin{tabular}{lllllll} 
Group & Sample size & Mean & S.D. & Variance & t-value & Remarks \\
\hline Control & 34 & 19.4 & 1.58 & 2.64 & 10.94 & $10.94>2.00$ \\
Experimental & 34 & 23.45 & 1.44 & 2.08 & &
\end{tabular}

$\mathrm{t}_{0.05,66=2.00}$

Table 2 shows that the mean scores of post-test of control and experimental group students were 19.4 and 23.45 respectively. The calculated standard deviation and variance were found to be 1.58 and 2.64 for control group respectively. While the calculated standard deviation and variance was found to be 1.44 and 2.08 for experimental group respectively. The calculated $\mathrm{t}$-value was found to be 10.94 which is greater than the tabulated value $(\mathrm{t}=$ $2.00)$ at 0.05 level of significance using two tailed test with degree of freedom 66 . This shows that there was significant difference between control and experimental group students' achievement after treatment. Hence, the null hypothesis was rejected and alternative hypothesis was accepted.

\section{Science teachers' attitude towards the participation of students in ICT}

The following table presents the teachers' attitude towards the participation of students in ICT, and chi-square value of each statement:

Table 3. Attitude of science teachers towards the participation of students in ICT

\begin{tabular}{llllllllll}
\hline Statements & \multicolumn{3}{l}{ Responses } & \multicolumn{3}{c}{$\chi^{2}$} & Decision & $\%$ \\
\cline { 2 - 9 } & SA & A & N & DA & SDA & & & \\
\hline It is easy to teach through ICT & 14 & 11 & 4 & 1 & - & 19.66 & $\mathrm{~S}$ & 83.33 \\
ICT gen erates motivation & 14 & 11 & 4 & 1 & - & 19.66 & $\mathrm{~S}$ & 83.33 \\
ICT helps to provide feedback & 14 & 11 & 4 & 1 & - & 19.66 & $\mathrm{~S}$ & 83.33 \\
\hline
\end{tabular}

From the Table 3 , it is concluded that the all the statements are significant with $\chi^{2}$ value 19.66 at 0.05 level of significance. From the total sample teachers $83.33 \%$ of sampled teachers are agreed with these above statements. Hence majority of teacher has positive attitude towards participation of students by ICT. This indicates that ICT helps to increase participation of students' in classroom activities. 


\section{Science teachers' attitude towards the ICT as the instructional materials}

The following table presents the teachers' attitude towards the ICT as the instructional materials, and chi-square value of each statement:

\begin{tabular}{|c|c|c|c|c|c|c|c|c|}
\hline \multirow[t]{2}{*}{ Statements } & \multicolumn{5}{|c|}{ Responses } & \multirow[t]{2}{*}{$\chi^{2}$} & \multirow[t]{2}{*}{ Decision } & \multirow[t]{2}{*}{$\%$} \\
\hline & SA & A & $\mathrm{N}$ & DA & SDA & & & \\
\hline $\begin{array}{l}\text { ICT can be used as } \\
\text { instructional materials }\end{array}$ & 15 & 12 & 1 & 2 & - & 26.33 & $\mathrm{~S}$ & 90 \\
\hline ICT is helpful to the lesson & 22 & 3 & 4 & 1 & - & 49 & $\mathrm{~S}$ & 83.33 \\
\hline $\begin{array}{l}\text { ICT helps to evaluate the } \\
\text { students }\end{array}$ & 15 & 12 & 1 & 2 & - & 26.33 & $\mathrm{~S}$ & 90 \\
\hline
\end{tabular}

From Table 4, it is concluded that the all the statements are significant with $\chi^{2}$-value at 0.05 level of significance. From the total sample teachers $90 \%$ of sampled teachers are agreed with ICT can be used as instructional materials and ICT help to evaluate students' performance, $83.33 \%$ of the sampled teachers are agreed with ICT is helpful to revise the lesson. Hence majority of teacher has positive attitude towards ICT as the instructional materials. This indicates that ICT can be used as instructional materials for science teaching learning.

\section{Science teachers' attitude towards the ICT as the motivational tools for the students}

The following table presents the teachers' attitude towards the ICT as the instructional materials, and chi- square value of each statement:

Table 5. Attitude towards the ICT as the motivational tools for the students

\begin{tabular}{llllllllll}
\hline Statements & \multicolumn{3}{c}{ Responses } & & & $\chi^{2}$ & Decision & $\%$ \\
\cline { 2 - 5 } & SA & A & N & DA & SDA & & & \\
\hline $\begin{array}{l}\text { ICT makes teaching more } \\
\text { interesting }\end{array}$ & 24 & 6 & & & - & 54 & $\mathrm{~S}$ & 100 \\
$\begin{array}{l}\text { ICT makes the lesson } \\
\text { more fun }\end{array}$ & 18 & 7 & 5 & & - & 34.33 & $\mathrm{~S}$ & 83.33 \\
$\begin{array}{l}\text { ICT generates teaching } \\
\text { learning }\end{array}$ & 17 & 5 & 4 & 2 & - & 24.33 & $\mathrm{~S}$ & 73.33 \\
\hline
\end{tabular}

From Table 5, it is concluded that the all the statements are significant with $\chi^{2}$-value at 0.05 level of significance. From the total sample teachers $73.33 \%$ of sampled teachers are agreed with ICT generates teaching learning, $83.33 \%$ of the sampled teachers are agreed with ICT makes the lesson more fun and $100 \%$ of the teachers are agreed with the ICT makes teaching more interesting. Hence majority of teacher has positive attitude towards ICT as the motivational tools for the students. This indicates that ICT helps to increase motivation of students' in science classroom activities.

Researcher had used Ellis's Model for Multimedia Effectiveness, the cognitive and cognitive constructive theories of multimedia learning as instructional methods whose primary goal is to foster meaningful learning. An instructional method is a way of presenting a lesson; it does not change the content of the lesson-the covered content is the same. 
Following Ellis's model, researcher conducted a study on how effective media-rich animations are in helping students learn and apply various algorithms. Media elements include text, graphics, voice narrations, interactive self-check quizzes requiring significant learners' active participation in the learning process.

In Cognitive Theory of multimedia, both non-interactive multimedia environments and interactive media environments were used. The results show students who learn from interactive (graphics and narration) learn more deeply and perform better on problem-solving transfer tests than students who learn from non-interactive (graphics and on-screen text)(Mayer \& Moreno, 1999).

Similarly, cognitive constructive theory of multimedia learning views learning as a complex situation in which the learners must actually re-construct the knowledge on their own terms through an active intellectual process. When using the constructivist approach students must grapple and struggle with material (ideas, concepts, facts) in order for this knowledge to be internalized. Researcher can utilize interactive multimedia to support an appropriate level of guidance through the use of feedback, markers and annotations to help learners in constructing their own view of the knowledge. An important element of the construction of ideas is visualization and practice, features which multimedia applications can support very well(Adams et al., 1996).

\section{Conclusion}

From the above data analysis of the study, it is found that there is no significant difference between without using multimedia projector (control group) and with using multimedia projector (experimental group) of both of school in pre-test. After analysis and interpretation of collected data, the post-test result indicates there is significant difference between pre-test and post-test result. The post-test results were found to be better than pretest results. Hence, it is concluded that, use of constructivist strategies is more effective than traditional strategies at secondary science teaching

From the above findings of this study, it is concluded that the secondary level science teachers have positive attitude towards ICT in teaching science. Furthermore, this study also shows that ICT can be used as the important teaching materials.

\section{Acknowledgements}

The author acknowledges the Center for Research, Rector Office, Tribhuvan University, Nepal for providing financial assistance to conduct this research under mini research grant.

\section{References}

Abas, Z. W., Osman, R., Kumar, P. R., \& Thangapragasam, S. (2007). Effectiveness of multimedia courseware design: Towards quality learning in ODL. Paper presented at the Proceedings of 21st annual conference of Asian association of open universities.

Adams, E. S., Carswell, L., Kumar, A., Meyer, J., Ellis, A., Hall, P., \& Motil, J. (1996). Interactive multimedia pedagogies: report of the working group on interactive multimedia pedagogy. ACM SIGCSE Bulletin, 28(SI), 182-191. Baddeley, A. (1983). Working memory. Oxford, England: Oxford University Press.

Bull, P. H. (2012). Using spatial constructivist thinking theory to enhance classroom instruction for students with special needs. In Communication technology for students in special education and gifted programs (pp. 66-81). IGI Global. Siddhajyoti Interdisciplinary Journal, Volume 2, January, 2021 
Clark, J. M., \& Paivio, A. (1991). Dual coding theory and education. Educational Psychology Review, 3(3), 149-210.

Fenrich, P. (1998). Practical guidelines for creating instructional multimedia applications: Dryden Press.

Gertner, R. T. (2011). The effects of multimedia technology on learning. Abilene Christian University USA,

Junaidu, S. (2008). Effectiveness of multimedia in learning and teaching data structures online. Turkish Online Journal of Distance Education, 9(4), 97-107.

Lee, J. K. (2002). Digital history in the history/social studies classroom. The History Teacher, 35(4), 503-517.

Lee, Y., \& Keckley, K. (2006). Effects of a Teacher-Made Multimedia Program on Teaching Driver Education. Teaching Exceptional Children Plus, 2(5).

Leser, R., Baca, A., \& Uhlig, J. (2011). Effectiveness of multimedia-supported education in practical sports courses. Journal of Sports Science \& Medicine, 10(1), 184.

Malik, S., \& Agarwal, A. (2012). Use of multimedia as a new educational technology tool-A study. International Journal of Information and Education Technology, 2(5), 468.

Mayer, R. E. (1996). Learning strategies for making sense out of expository text: The SOI model for guiding three cognitive processes in knowledge construction. Educational Psychology Review, 8(4), 357-371.

Mayer, R. E. (1999). Research based principles for the design of instructional messages: The case of multimedia explanations. Document Design, 1(1), 7-20.

Mayer, R. E. (2002). Cognitive theory and the design of multimedia instruction: an example of the two way street between cognition and instruction. New Directions for Teaching and Learning, 2002(89), 55-71.

Mayer, R. E. (2003). Elements of a science of e-learning. Journal of Educational Computing Research, 29(3), 297-313.

Mayer, R. E. (2005). Cognitive theory of multimedia learning. The Cambridge handbook of multimedia learning, 41, 31-48.

Mayer, R. E., \& Moreno, R. (1998). A split-attention effect in multimedia learning: Evidence for dual processing systems in working memory. Journal of Educational Psychology, 90(2), 312

Mayer, R. E., \& Moreno, R. (1999). Nine Ways to Reduce Cognitive Load in Multimedia Learning. Educational Psychologist, 38(1), 43-52.

Mayer, R. E., \& Moreno, R. (2003). Nine ways to reduce cognitive load in multimedia learning. Educational Psychologist, 38(1), 43-52.

Mayer, R. E., Moreno, R., Boire, M., \& Vagge, S. (1999). Maximizing constructivist learning from multimedia communications by minimizing cognitive load. Journal of Educational Psychology, 91(4), 638.

Mohan, R. (2013). Innovative Science Teaching for Physical Teachers. New Delhi: PHI Learning Private Limited.

Moreno, R. (2004). Multimedia learning. New York: Cambridge University Press

Munir. (n.d.). The effectiveness of multimedia in education package to motivate literacy (MEL) amongst preschool student. 13, 1-9.

Musker, R. (2004). Using ICT in a secondary Science. Teaching Secondary Science with ICT, 7.

National Art Education Association. (2011). Learning in a visual age: The critical importance of visual arts education: National Art Education Association. 
Neupane, S. (2014). Using Inexpensive Technology and Multimedia To Improve Science Education In Rural Communities Of Nepal. McGill Journal of Education / Revue des sciences de l'éducation de McGill, 49(3), 697-706.

Nugent, G. C. (1982). Pictures, audio, and print: Symbolic representation and effect on learning. ECTJ, 30(3), 163-174.

Paivio, A. (1986). Mental representations: A dual coding approach. Oxford, England: Oxford University Press.

Rajasekar, S., \& Vaiyapuri, R. (2008). Higher Secondary Teachers' Computer Anxiety. Edu Tracks, 7(8), 39-40.

Sapkota, B. (2015). Effectiveness of information communication Technology Integrated Pedagogy at Secondary Level.

Shah, I., \& Khan, M. (2015). Impact of multimedia-aided teaching on students' academic achievement and attitude at elementary level. US-China Education Review A, 5(5), 349-360.

Somekh, B., Haldane, M., Jones, K., Lewin, C., Steadman, S., Scrimshaw, P., . . Downing, B. (2007). Evaluation of the primary schools whiteboard expansion project. Retrieved from London:

Sweller, J. (1988). Cognitive load during problem solving: Effects on learning. Cognitive Science, 12(2), 257-285.

Sweller, J. (1994). Cognitive load theory, learning difficulty, and instructional design. Learning and Instruction, 4(4), 295-312.

Syazwan, N., Wan Ahmad, W. F., \& Yew, K. H. (2011). Study of effectiveness and usability of multimedia courseware integrated with 3-dimensional model as a teaching aid. International Journal of Computer Applications, 16(4), 20-27.

Taber, K. S. (2006). Beyond constructivism: The progressive research programme into learning science.

Van Eeden, E. S. (1999). Didactical guidelines for teaching history in a changing South Africa: Keurkopie Uitgewers.

Vanaja, M., \& Rajasekar, S. (2007). Educational Technology \& Computer Education: Neelkamal Publications.

\section{About the Author}

Bishnu Kumar Dahal is Associate Professor of Science Education at Mahendra Ratna Campus,

Tahachal, Tribhuvan University, Nepal. He has completed Master's Degree in Physics from

Tribhuvan University. He is currently a Ph. D. scholar in Science Education at Tribhuvan

University. His work focuses specifically on the innovative pedagogical strategies to enhance cognitive development of concerned stakeholders in science education. 